CDAP-TR-046

for U.S. Nuclear Regulatory Commission

\title{
CODE DEVELOPMENT AND ANALYSIS PROGRAM BEACON/MOD2A ANALYSIS OF THE ARKANSAS-1 REACTOR CAVITY DURING A HYPOTHETICAL HOT LEG BREAK
}

J. A. RAMSTHALER

\section{MASTER}

January 1979

EG\&G Idaho, Inc.

\section{DEPARTMENT OF ENERGY}




\section{DISCLAIMER}

This report was prepared as an account of work sponsored by an agency of the United States Government. Neither the United States Government nor any agency Thereof, nor any of their employees, makes any warranty, express or implied, or assumes any legal liability or responsibility for the accuracy, completeness, or usefulness of any information, apparatus, product, or process disclosed, or represents that its use would not infringe privately owned rights. Reference herein to any specific commercial product, process, or service by trade name, trademark, manufacturer, or otherwise does not necessarily constitute or imply its endorsement, recommendation, or favoring by the United States Government or any agency thereof. The views and opinions of authors expressed herein do not necessarily state or reflect those of the United States Government or any agency thereof. 


\section{DISCLAIMER}

Portions of this document may be illegible in electronic image products. Images are produced from the best available original document. 


\section{NOTICE}

This report was prepared as an account of work sponsored by the United States Government. Neither the United States nor the Department of Energy, nor the Nuclear Regulatory Commission, nor any of their employees, nor any of their contractors, subcontractors, or their employees, makes any warranty, express or implied, or assumes any legal liability or responsibility for the accuracy, completeness or usefulness of any information, apparatus, product or process disclosed, or represents that its use would not infringe privately owned rights. 
-NRM EG8 G-398

ev 12-78)
INTERIM REPORT
Accession No.

Report No. CDAP-TR-046

$\because$ Contract Program or Project Title: Containment Ana lys is Development

Subject of this Document:

BEACON/MOD2A Analysis of the Arkansas-1 Reactor Cavity During a Hypothetical Hot Leg Break

Type of Document: Status Report

Author(s): J. A. Ramsthaler

This report was prepared as sponsored by the United States Government Neither the United States nor the United States Departmert of Energy, nor any of their employees, nor any of their contractors, subcontractors or their employes, makes any warranty, express or implied, or assumes, an lese liability or responsibility for the accuracy, completegal or usefulness of any information accuracy, completeness process disclosed, or represents that its use product or infringe privately owned rights. that its use would not infringe privately owned rights.

Date of Document: January 1979

Responsible NRC Individual and NRC Office or Division: S. Fabic, Reactor Safety Research

This document was prepared primarily for preliminary or internal use. It has not received full review and approval. Since there may be substantive changes, this document should not be considered final.

EG\&G Idaho, Inc. Idaho Falls, Idaho 83401

Prepared for the U.S. Nuclear Regulatory Commission and the U.S. Department of Energy Idaho Operations Office Under contract No. EY-76-C-07-1570 NRC FIN No.

INTERIM REPORT

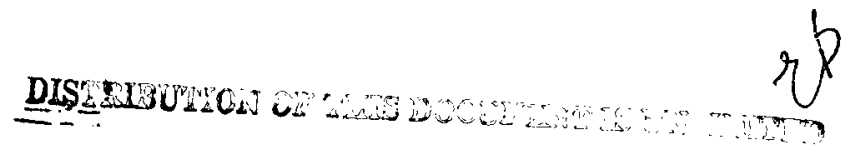


BEACON/MOD2A ANALYSIS OF THE ARKANSAS-1

REACTOR CAVITY DURING A HYPOTHETICAL

HOT LEG BREAK

J. A. RAMSTHALER 


\section{SUMMARY}

A best estimate transient containment code, BEACON, is being developed by EG\&G Idaho, Inc. for the Nuclear Regulatory Commission's reactor safety research program. In support of this development effort there has been an ongoing concurrent evaluation and verification of the code prior to releasing a new version in late 1978. Part of this effort was to evaluate the code capabilities, to determine its suitability for modeling different types of containment problems, and to establish guidelines for future use.

As part of the evaluation of the new MOD2A version of the code, the Arkansas-1 reactor cavity was modeled during a hypothetical lossof-coolant accident. Results of the BEACON analys is were compared with results obtained previously with the COMPARE containment code. This comparison was done to illustrate the differences between predictions from a dynamic, non-homogeneous, non-equilibrium, twodimensional code such as BEACON and a stagnant, homogeneous, equilibrium code such as COMPARE. Studies were also made investigating some of the BEACON interphasic, timestep control, and wall heat transfer options to assure that these models were working properly and to observe their effects on the results.

Descriptions of the Arkansas-1 reactor cavity, initial assumptions during the hypothetical LOCA, and methods of modeling with BEACON are presented. Some of the problems encountered in accurately modeling the penetrations surrounding the hot and cold leg pipes are also discussed. A best estimate model was developed using the results of a previous BEACON comparison with data from a large flashing jet experiment. This model represented the BEACON best estimate of predicted cavity pressures during the LOCA and was used for the COMPARE code comparison. 
The calculated pressures within the cavity initially peaked at about 0.01 second using both the BEACON best estimate model and the COMPARE code. At this time, and throughout the LOCA, peak pressures predicted for the cavity using the BEACON best estimate model were about $50 \%$ lower than the corresponding pressures obtained with COMPARE. Pressure distributions around the annulus were similar using both codes, except for magnitude. The lower pressures were the result of the non-homogeneous, flashing rate, and dynamic flow capabilities available in BEACON.

A comparison of the predicted force and moment loads on the Arkansas- 1 pressure vessel showed similar differences between BEACON and COMPARE. Peak horizontal forces on the vessel were significantly smaller with BEACON while vertical forces were slightly larger. The non-homogeneous features of BEACON allowed greater flow to the lower sub-cavity of the reactor than COMPARE. The predicted lower cavity pressures and higher sub-cavity pressures then resulted in the corresponding differences in the horizontal and vertical forces on the vessel. As a result, the peak moment loads on the vessel were significantly less with BEACON than with COMPARE. The BEACON predictions are believed to be closer to the actual loads expected in the cavity because of the dynamic, two-dimensional, non-homogeneous features in this code.

Variations from the best estimate model were then used to investigate the code sensitivity to flashing rate, interphasic drag, heat transfer rate, and timestep control parameters. In these parametric studies, the largest variations in the BEACON peak pressures were observed when either the flashing rate or drag coefficient was varied. Conversely, only small changes in peak pressures (less than 10\%) were obtained by varying the interphasic heat transfer rate before the code became unstable. For this problem, predicted 
pressures appeared to be controlled more by phase change and interphasic coupling effects than by heat transfer considerations. Small increases in initial peak pressures (less than 10\%) were observed when BEACON was run with a constant timestep rather than the auto-timestep, but after about 0.02 second the differences were indiscernible. Large savings in computer time with only small variations in results were effected by carefully choosing the Courant restriction multiplier and the relaxation parameter.

The new MOD2A film and heat structure options were also investigated and resulted in negligible changes. The large mass flows and short problem time caused wall heat transfer effects to be insignificant.

The Arkansas-1 study indicates that modeling a LOCA with BEACON is straightforward; however, further development of the flashing and drag models needs to be investigated. Also, addition of a pseudo three-dimensional outflow option would increase the flexibility of the code in simulating pipe penetrations from the cavity. All of the models used in the analys is appear to be working properly, with the possible exception of the interphasic heat transfer option. The results appear to be consistent with expected physical phenomena. 


\section{CONTENTS}

SUMMARY . . . . . . . . . . . . . . . . . . . . . j

I. INTRODUCTION . . . . . . . . . . . . . . . . . 1

II. DESCRIPTION OF THE ARKANSAS-1 REACTOR CAVITY DURING THE HYPOTHETICAL HOT LEG BREAK . . . . . . . . . . . . . . . 4

III. MODEL ING THE ARKANSAS- 1 HOT LEG BREAK WITH BEACON. . . . . . 7

1. General Modeling Description. . . . . . . . . . . 7

2. BEACON Best Estimate Model.............. 10

3. Parametric Studies. . . . . . . . . . . . 11

IV. RESULTS OF THE ANALYSIS. . . . . . . . . . . . . 12

1. BEACON Best Estimate Mode1.............. 12

2. Force and Moment Loads on the Reactor Pressure Vessel . . 18

3. Parametric Studies. . . . . . . . . . . . 20

V. CONCLUSIONS AND RECOMMENDATIONS. . . . . . . . . . . . 28

VI. REFERENCES . . . . . . . . . . . . . . . . 31

Appendix A - BEACON INPUT .................... A- . . 


\section{FIGURES}

1. Schematic of the Arkansas-1 reactor cavity showing the location of the hypothetical hot leg break ...... 5

2. BEACON nodalization diagram for the Arkansas-1 reactor cavity....................... 8

3. Comparison between the BEACON and COMPARE predictions of peak cavity pressures during the LOCA . . . . . 15

4. BEACON and COMPARE predictions of pressures around the annulus at break height showing similar distributions but different magnitudes ............

5. Pictorial representation of the relative vapor velocities which contribute to the lowered cavity pressures in the BEACON calculations ..........

6. Comparison of BEACON and COMPARE calculated forces on the reactor pressure vessel during the hypothetical LOCA. ...................

7. Comparison of BEACON and COMPARE calculated moment loads on the reactor pressure vessel during the hypothetical LOCA. . . . . . . . . . . .

8. BEACON peak cavity pressure variations with changes in the flashing rate multiplier (LAMBDA) .........

9. BEACON peak cavity pressure variations with changes in the interphasic drag parameter (KDRAGI) ....... 
10. BEACON results showing the effect that timestep has on calculated peak pressures........... 25

A-1. BEACON input card listing for the Arkansas-1 cavity hot leg break best estimate model. . . . . . . . A-2

TABLES

I. Summary of BEACON Computer Runs. ............ 13 


\section{BEACON/MOD2A ANALYSIS OF THE ARKANSAS-1 \\ REACTOR CAVITY DURING A HYPOTHETICAL \\ HOT LEG BREAK}

\section{INTRODUCTION}

The identification of potential safety problems that may arise in PWR pressure vessel support systems during loss-of-coolant accidents (LOCA's) is a primary concern in the reactor safety research program. In support of this task, the United States Nuclear Regulatory Commission (USNRC) has recently contracted EG\&G Idaho, Inc. to model the Arkansas-1 reactor cavity and to analyze loads resulting from postulated primary coolant pipe breaks. This investigation was initiated to determine whether transient differeilial pressures within the annulus between the reactor vessel and the cavity shield wall could result in asymmetric loads exceeding the design limits of the plant. Results from analyses such as these will be used to evaluate the design adequacy of existing and future PWR power plants.

In order to identify these potential loading transients, the Arkansas-1 cavity was modeled during hypothetical double-ended hot and cold leg pipe breaks using the COMPARE [1] containment code. This study was performed by the Containment Code Development Program at the request of the Applied Mechanics Branch at EG\&G Idaho, Inc. The resultant force and moment loads predicted during this analys is are given in Reference 2.

A separate analysis of the Arkansas-1 reactor cavity during the hypothetical hot-leg break was then performed using the BEACON/MOD2A containment code. This analysis was done as part of the evaluation 
and verification of this recently released version of the code during the final stages in its development [a]. The hot leg break was chosen for the analysis, over the cold leg break, because of the larger predicted mass flow and energy rates for this LOCA. Arkansas -1 has two large hot legs and four smaller cold legs, thus, the greater hot leg flow rate per pipe.

BEACON/MOD2A is a dynamic, two-component, two-phase best estimate code used to model relatively short-term transients during a LOCA. Fluid flow and resulting temperatures and pressures can be predicted in dry PWR containment buildings by using one-dimensional, twodimensional, and lumped parameter modeling. Non-equilibrium, two-phase phenomena can be simulated by utilizing the unequal velocity, unequal temperature features of the code. Also, wall film and heat structure options have been alded to the new MOD2A version of BEACON.

The purpose of the BEACON analys is of the Arkansas-1 LOCA was two-fold. First, an analys is was done to check out the general modeling features in the MOD2A version of BEACON and to demonstrate the differences between the BEACON and COMPARE containment codes. BEACON is a dynamic, two-dimensional, non-equilibrium code while COMPARE assumes a stagnant, homogeneous mixture in thermodynamic equilibrium. A BEACON best estimate model was developed and the calculated pressures and resulting force and moment loads were compared with the COMPARE predictions. Second, an investigation was done to evaluate several of the models and options in the code and to assure that they were operating satisfactorily. A series of BEACON runs was made investigating some of the interphasic, timestep control, and wall heat transfer parameters.

[a] A developmental version of BEACON/MOD2A (Configuration Control Number H00600IB) was used for this report. The final version of the code was released in late 1978. The released version of MOD2A should be identical to this version with the possible exception of minor coding corrections. 
This report documents the results of the BEACON/MOD2A analysis of a hypothetical hot leg break at the Arkansas-1 reactor. A description of the reactor cavity during the postulated LOCA is given in Section II and the BEACON modeling description is given in Section III. Results of the analysis and conclusions and recommendations are presented in Sections IV and $V$, respectively. 


\section{DESCRIPTION OF THE ARKANSAS- 1 REACTOR CAVITY DURING THE HYPOTHETICAL HOT LEG BREAK}

For this analysis, the Arkansas-1 reactor was assumed to undergo a double-ended hot leg pipe break at full power. The full displacement rupture occurred within the cavity and was analyzed for the first 2 seconds of the LOCA. A blowdown table, supplied by the USNRC, was the source of the predicted mass flow rates and specific enthalpies used for this report [2].

The area of interest in the BEACON analysis of Arkansas-1 during the postulated LOCA consists of the annular region located between the reactor pressure vessel and the shield wall (Figure 1). The annulus is penetrated horizontally by two hot lisy, four cold leg, and two core flooding pipes. In addition, several instrumentation pipes run vertically up the cavity wall, protruding partially into the annulus. During a LOCA, flow could exit the cavity through the pipe penetrations into the containment or through the twelve openings in the vessel skirt into the lower sub-cavity. Flow from the sub-cavity could then exit through the instrument tunnel into the containment.

The following assumptions were made for this analysis:

(1) Initial cavity conditions were $0.101 \mathrm{MPa}, 311 \mathrm{~K}$, and $100 \%$ relative humidity.

(2) Rupture of the hot leg pipe occurred entirely within the cavity confines. 


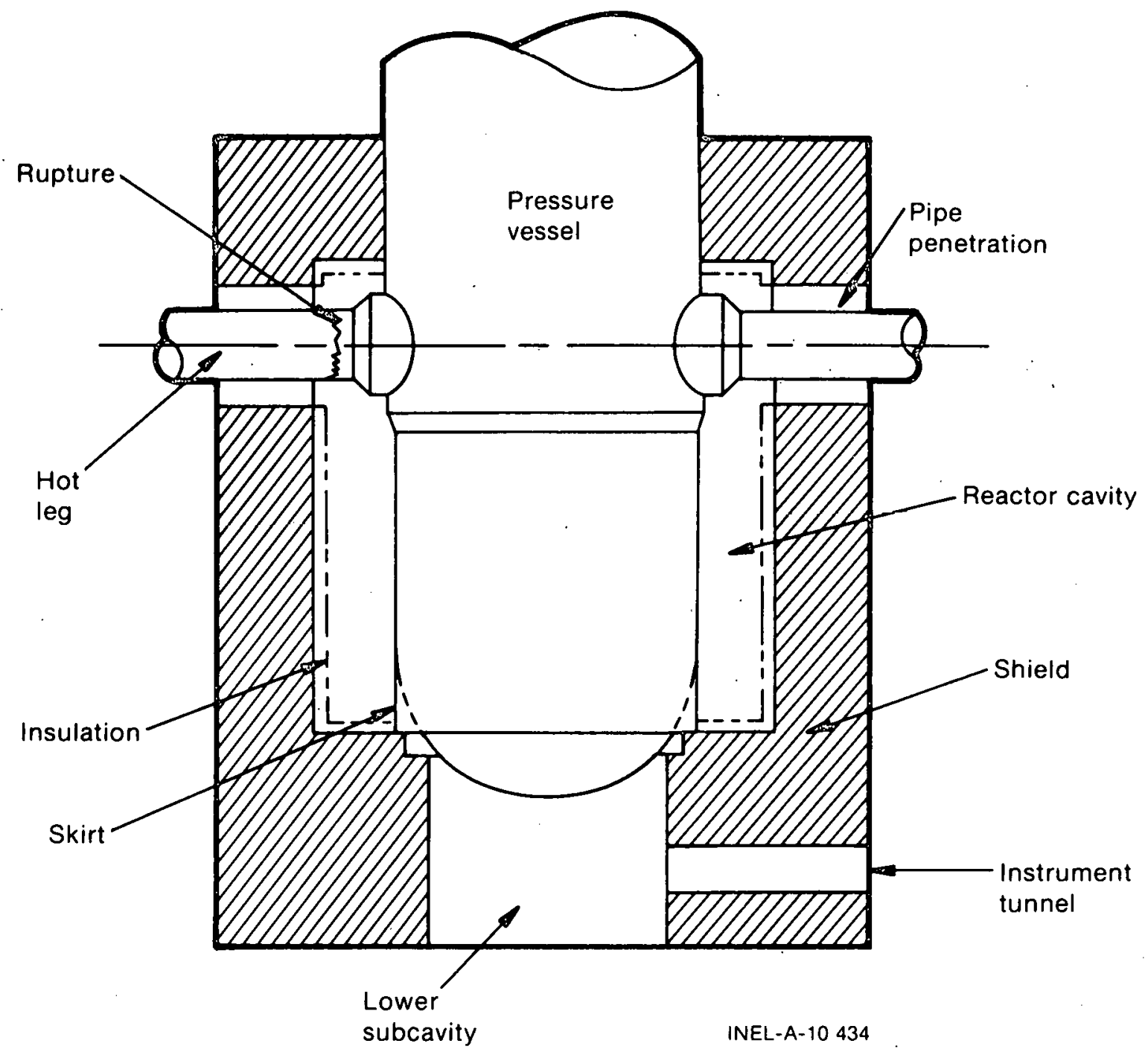

Fig. I Schematic of the Arkansas-1 reactor cavity showing the location of the hypothetical hot leg break. 
(3) The cavity top plug was considered to remain in place during. the postulated LOCA, therefore, the large hot and cold leg pipe penetrations served as the primary exits from the cavity.

(4) Insulation on the pipes was assumed to remain intact and the cavity insulation was assumed to be blown to the outer walls.

(5) The twelve openings ( $0.235 \mathrm{~m}$ diameter each) from the vessel skirt into the sub-cavity were combined into four openings of equivalent total flow area.

(6) The core flooding pipes were ignored because of their small size. 
First, the general modeling of the Arkansas-1 geometry was accomplished, and then the BEACON best estimate model for the problem was set up. This model was used for comparisons with the COMPARE results and for general evaluation of the code. Next, variations in several of the interphasic and timestep control parameters were made to investigate these options. Finally, the new wall heat transfer capabilities of the code were investigated by selecting the wall film and heat structure options.

\section{GENERAL MODELING DESCRIPTION}

The first step in setting up the problem consisted of unfolding the annulus into a rectangular volume of equivalent dimensions to the Arkansas-1 cavity. Since the problem was symmetric about the hot leg break, half of the annulus was modeled by splitting it vertically through one of the hot leg pipes (Figure 2). Some of the stipulations used in modeling are listed below:

(1) The mesh was developed to model the flow area of the break and the cross-sectional areas of the pipes as accurately as possible.

(2) The hot and cold leg pipes penetrating the cavity horizontally and the instrument tubes running up the walls of the cavity were represented by the partial flow blockage option in the code. 
Constant pressure boundary

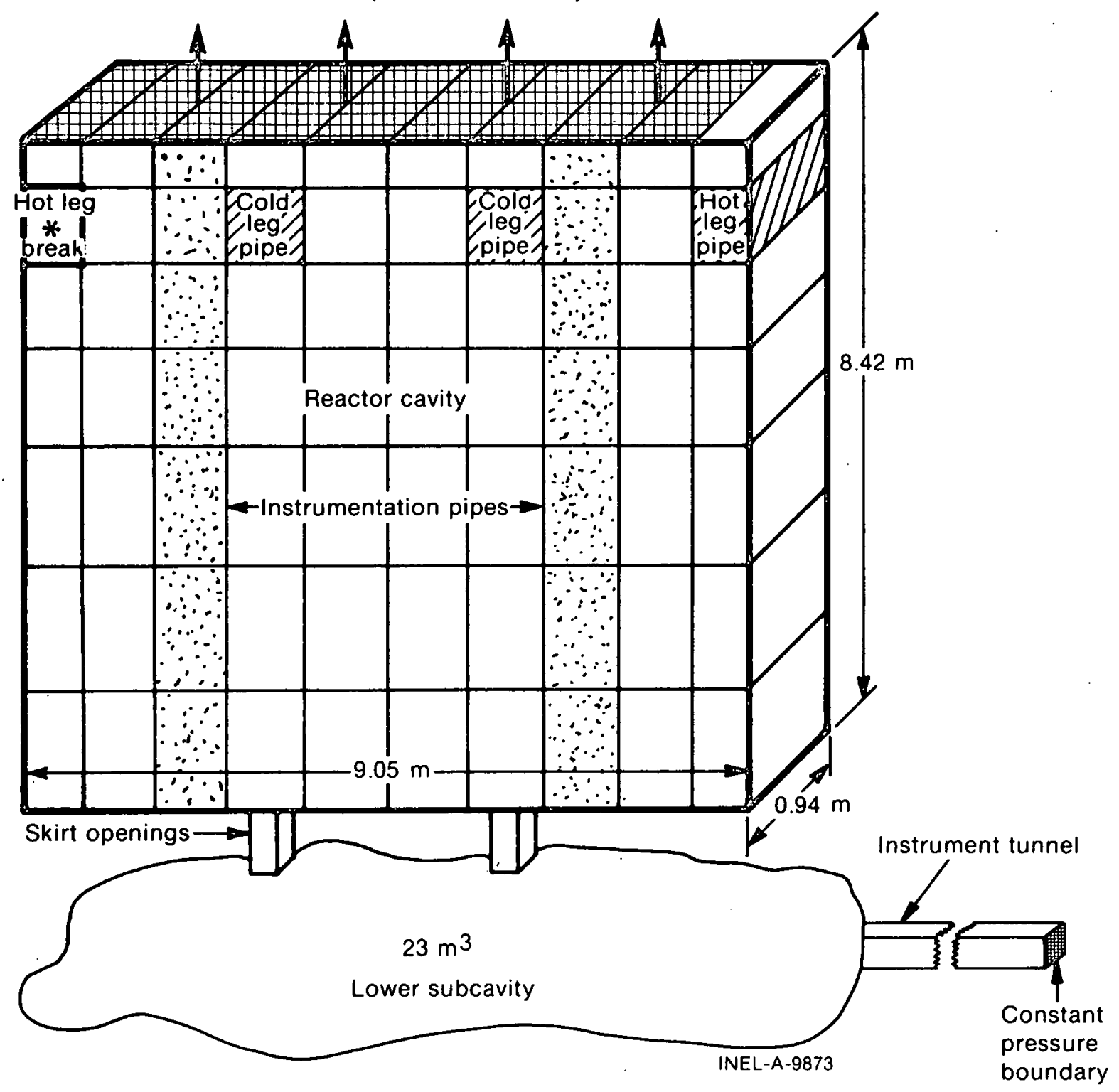

Fig. 2 BEACON nodalization diagram for the Arkansas-1 reactor cavity. 
(3) One of the limitations of BEACON is that outflows cannot be modeled, except at the boundaries of a mesh, unless the exiting mass flow rates, enthalpies, velocities, etc. are known. Therefore, in order to model the free-flow from the hot and cold leg pipe penetrations, a constant pressure boundary was created at the top of the cavity mesh (Figure 2). The flow area of this boundary was made equivalent to the sum of the flow areas of the respective penetrations. Previously, an attempt was made to model the penetrations with one-dimensional meshes attached to the upper boundary above each pipe. Because of the large flow areas of these penetrations, this method would have required that the one-dimensional meshes have depths greater than that of the cavity, resulting in erroneous flow areas where the 1-D regions joined the cavity. A second attempt was made to model the penetrations with an outflow boundary. This method was not considered acceptable because of the way BEACON handles this type of boundary. With this option, the code sets the ficticious boundary cells equal in pressure to he adjacent interior cells. Because of the large size of the containment collecting this outflow (nearly $65,000 \mathrm{~m}^{3}$ ), the actual pressures of the exterior boundary cells should be nearly ambient. For these reasons, constant pressure boundaries were used for both the cavity penetration and instrument tunnel exits.

(4) Since the skirt openings were near the bottom of the cavity, and were of small flow area, they were modeled as onedimensional pipes into the lower sub-cavity. The sub-cavity was then represented by a lumped parameter region. Because these openings actually exit horizontally from the skirt but were modeled with vertical meshes, the gravity option was not used. 
(5) The Rivard model for mass transfer was used in determining the flashing rate and constant drag was assumed for this report.

\section{BEACON BEST ESTIMATE MODEL}

A BEACON best-estimate model was developed for the general code evaluation and to make a comparison with the COMPARE code results. The geometry and assumptions used in setting up this model were as described in Sections II and III.1. Input concerning the interphasic parameters were chosen on the basis of an experimental test. The BEACON automatic timestep option was selected and the calculations were run for the first 2 seconds of the hypothetical LOCA. The automatic option causes the timestep to be calculated internally by the code, based on given restrictions. Input to BEACON for the best estimate model is given in Figure $A-1$.

Results from a previous BEACON study of a large subcooled jet, Battelle-Frankfurt Experiment $\mathrm{C}-12$, were used in modeling the flashing rate multiplier, drag parameter, and interphasic heat transfer rate. In the $\mathrm{C}-12$ analysis, a study was done comparing BEACON pressure predictions with experimental data $[3]$. The particle density was arbitrarily assumed constant and the flashing rate (LAMBDA) and interphasic drag parameter (KDRAGI) were then varied parametrically. Values of $\angle A M B D A=0.015$, KDRAGI $=2.2 E 8$ gave very good results when compared with test data. The interphasic heat transfer rate (RHEATI= 1.0E20) was also taken from the $\mathrm{C}-12$ analysis. Because of the similarities between this large jet experiment and the postulated hot leg break, and because no other data comparisons were available, the Arkansas- 1 best estimate model was set up with the above values. 


\section{PARAMETRIC STUDIES}

Parametric studies were done to evaluate the effects of the flashing rate, interphasic drag, heat transfer rate, and timestep parameters on the BEACON results. The best estimate model was used with variations in the parameter of interest. The film and heat structure options were also investigated to assure that the wall heat transfer models were working correctly. For the most part, the parametric studies were carried out for the first 0.05 second of the LOCA. 
The BEACON analysis of the Arkansas-l hypothetical LOLA was essentially divided into three parts:

(1) Predicted pressures using the GEACON best estimate model were obtained and compared with those from the COMPARE code for the first 2 seconds of the LOCA

(2) The resulting force and monent loads on the reactor pressure vessel were calculated to determine possible loading transients during the LOCA

(3) The effects of varying the flashing. drag, interphasic heat transfer, and timestep control parameters and of adding wall heat transfer were investigated.

To obtain the BEACON results for this report twenty-one computer. runs were made. The objectives of each run. CPU tillle, and variation from the best estimate model are sumuarized in Table 1.

\section{BEACON BEST ESTIMATE MODEL}

The BEACON best estimate model and COMPARE code were run out to a problem time of 2 seconds. The BEACON calculations took 2923 seconds of CPU time while COMPARE took 611 seconds. However, the BEACON problem had 74 cells to compute versus 34 volumes in COMPARE. Indications are that the two-dimensional, dynamic, non-homogeneous features in BEACON required approximately double the computer time of COMPARE when using the timestep control paraneters shown for Run 1, Table I. 
TABLE I

SUMMARY OF BEACON COMPUTER RUNS.

\section{RUN
NO. OBJECTIVE \\ 1 Compare BEACON best est Imate model and est Imate model and
COMPARE results}

2 Investigate effects of varying the flashing

3 Same as above

4 Same as above

5 Same as above

6 Same as above

7 Investigate effects of varying the interphasic orag parameter

8 Same as above

9 Same as above

10 Same as above

1) Investigate effects of varying the overall interphasic heat transfer par ameter

13 Investigate the effects of varying the timestep control parameters

14 Same as above

15 Same as above

16 Same as above

17 Same as above

18 Same as above

19 Same as above

20 Same as above 21 Investigate the effects
of wall heat transfer
VARIATION FROM

\section{BEST ESTIMATE MODEL}

none

LAMBDA $=0.0$

LAMBDA $=0.1$

$\angle A M B D A=0.3$

LAMBDA $=1.0$

LAMBDA $=10.0$

KORAG $=0.0$

KORAG = $2.2 E 2$

KDRAG = 2.2E4

$K D R A G=2.2 E 10$

RHEATI $=1.0 E 10$

RHEAT 1 = 1.0E7

$\Delta \mathrm{T}=0.0001 \mathrm{~s}$

$\Delta T=0.00001 \mathrm{~s}$

XDTC $=0.5$

XDTC $=0.05$.

$X \mapsto O T=5.0$

XMT $=10.0$

ONEGA $=1.5$

OMEGA -2.0

Vall film and

heat structures
494 (0.025s)

CPU TIME (s)

2928 (2.0s problen time) 111 (0.05s problem time)

$29(0.05 s)$

$162(0.05 s)$

188 (0.05s)

$211(0.05 s)$

bombed

$156(0.05 s)$

$148(0.05 \mathrm{~s})$

116 (0.05s)

111 (0.05s)

112 (0.05s)

$120(0.055)$

$156(0.05 s)$

$747(2.05)$
$46(0.055)$

188 (0.05s)

$111(0.05 \mathrm{~s})$

111 (0.05s)

$248(0.05 s)$

Bombed

$171(0.05 s)$

\section{COMAENTS*}

$\angle A M B D A=0.015$, KDRAGI $=2.2 E B$, RHEATI $=1.0 \mathrm{E} 20$

$\triangle T$ = automatic timestep control, $\Delta T_{L P R}=0.001 \mathrm{~s}$, XOTC $=0.10$,

XMBF $=2.0,0 \mathrm{MEGA}=1.0$
FIGURE NUMBER(s)

3, 4, 5, 6, 7

Same results as Run I

Peak pressure at 0.015 is about $108 \mathrm{~h}$ igher than with auto-timestep

10

Peak pressure at $0.01 \mathrm{~s}$ is about

10

10 higher than with auto-timestep

Average 1terations per cycle $=47.5$ compared to 2.7 for best est imate model

Negligible effects

* Definition of terms:

LAMBDA = evaporation or flashing rate multiplier

KDRAGI - interphasic drag paraneter

KDRAGI = interphasic drag parameter
RHEATI = overall interphasic heat transfer rate per unit volume

$\Delta T_{L P R}$ a timestep interval in lumped parameter region

Xote - Courant restriction multiplier

XMOT multiplier used to restrict the increase in timestep

OMEGA - relaxation parameter for Iteration 
Initial peak cavity pressures obtained with both the BEACON best est imate model (Run 1, Table I) and the COMPARE code occurred at approximately 0.01 second in time (Figure 3 ). In each case, the predicted peak pressure occurred in the cell or volume closest to the hot leg break. BEACON values remained about $50 \%$ less than those using the COMPARE code for the entire LOCA. The peak seen at 0.4 second was due to a peak in the predicted mass flow rate used as input to both codes.

The pressure distribution around the annulus at the break level was similar using both BEACON and COMPARE, except for magnitude (Figure 4). BEACON results (Run 4, Table I) with a higher flashing rate multiplier (LAMBDA $=0.3$ ) were also plotted for reference. This run gave nearly the same peak cavity pressure at 0.01 second as the COMPARE results ( $3.2 \mathrm{MPa}$ ). The pressure distribution is again similar to that of COMPARE except at about two meters from the break where an inflection in the curve occurs. This is thought to be due to pressure oscillations caused by the higher evaporation rate.

Differences between the pressure results from the BEACON best estimate model and COMPARE code are thought to be due to the following effects:

(1) BEACON is a non-homogeneous code, therefore, during the first part of the LOCA there was little mixing of the hot steam $(577 \mathrm{~K})$ and the cool air $(311 \mathrm{~K})$. The cool air was more dense, thus allowing for a higher mass flow rate from the cavity exits at the same pressure differential. The resulting cavity pressures were lower than if a homogeneous, warmer, and less dense mixture were assumed as with the COMPARE code. A previous analys is comparing BEACON results with test data has shown that these non-homogeneous effects 


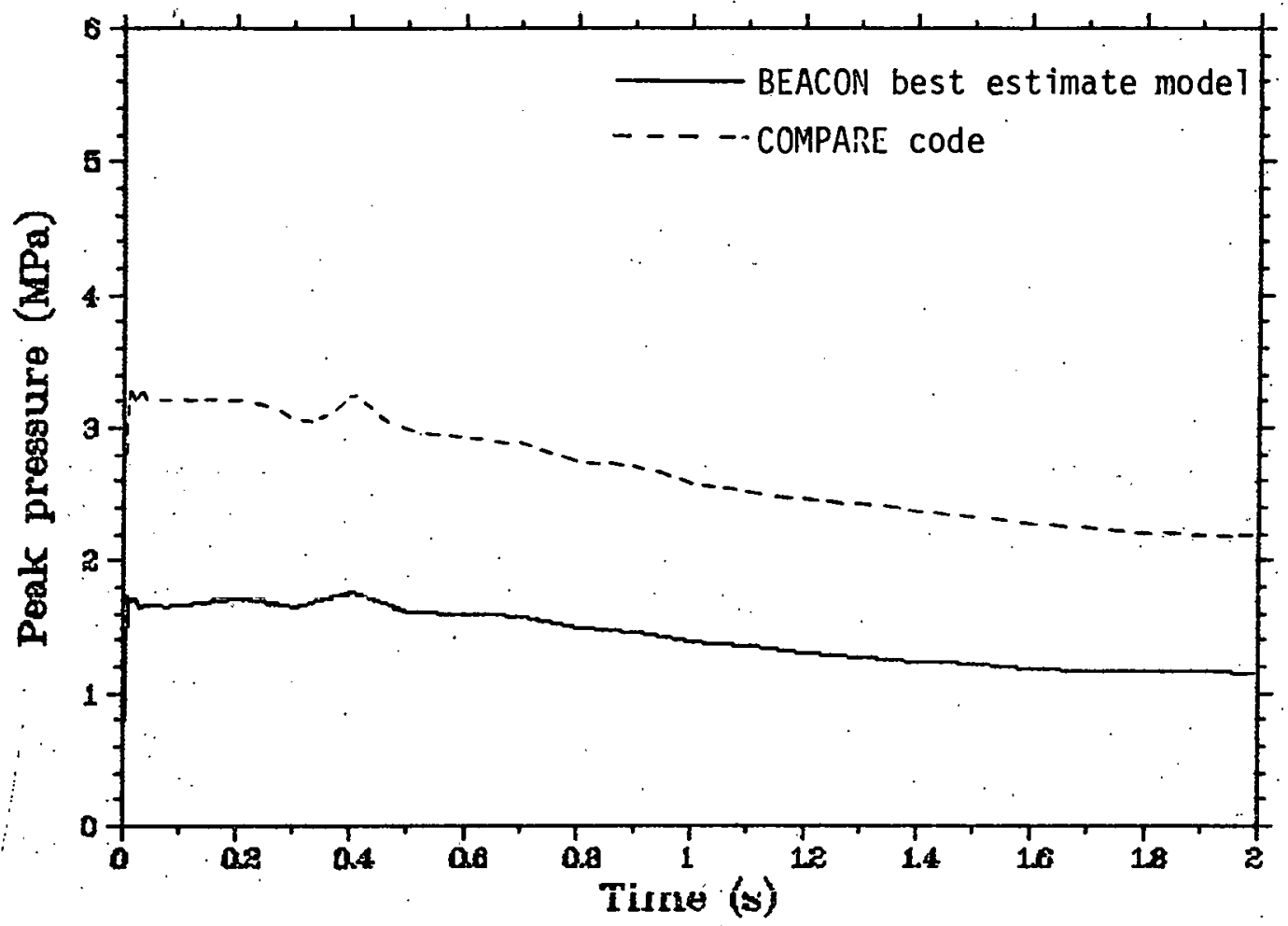

Fig. 3 Comparison between the BEACON and COMPARE predictions of peak cavity pressure during the LOCA. 


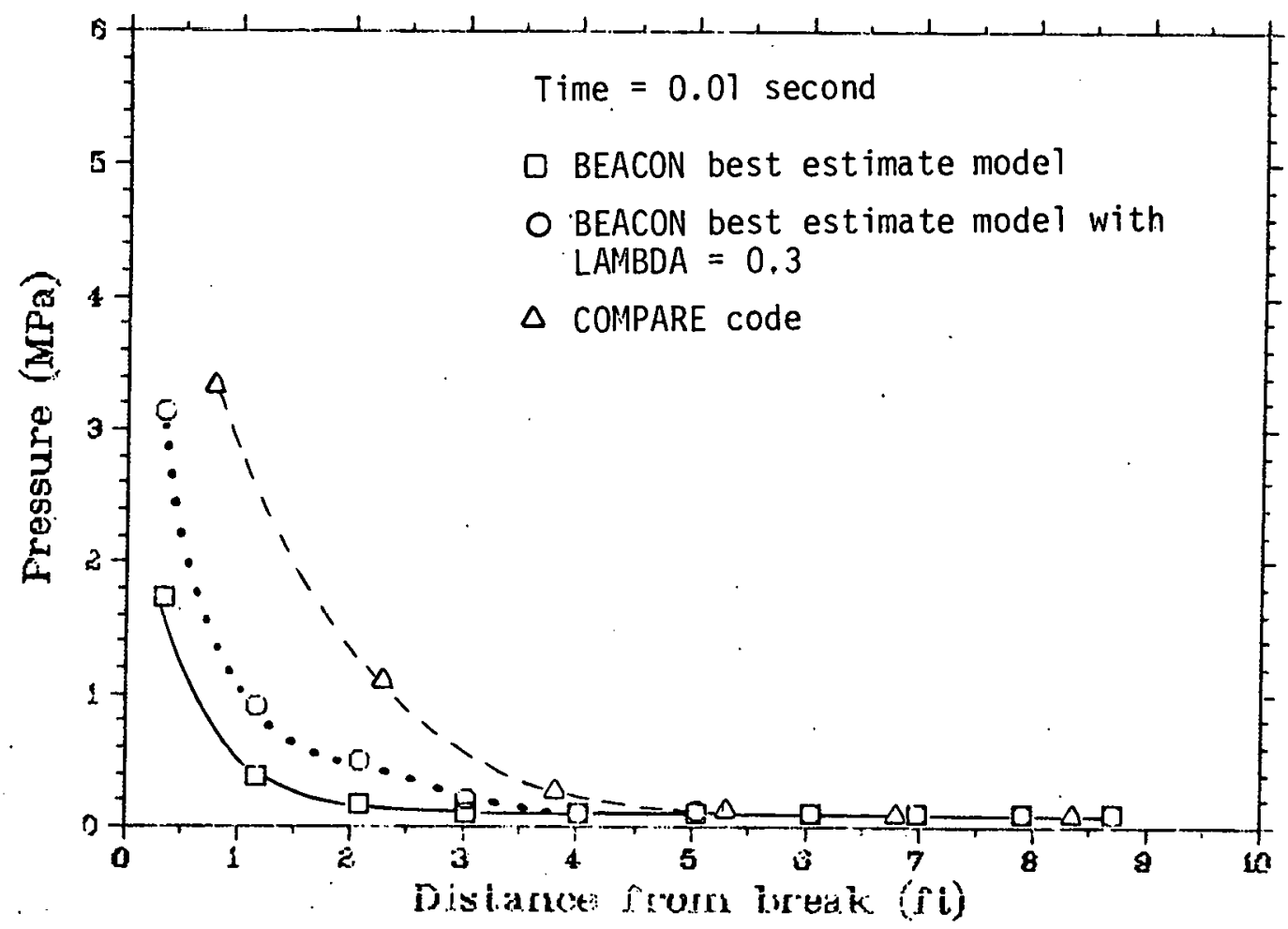

Fig. 4 BEACON and COMPARE predictions of pressures around the annulus at break height showing similar distributions but different magnitudes. 
are significant [4]. In this previous study, closer matching of test data was demonstrated when the BEACON nonhomogeneous features were ultilized than when only homogeneous conditions were assumed (lumped parameter modeling).

(2) With BEACON, the flashing rate parameter dictated a longer time before the hot water from the break flashed than with COMPARE which assumed instantaneous evaporation. This longer flashing rate resulted in part of the lowered pressures seen in the BEACON calculations.

(3) A velocity effect also results in lowered pressures in the BEACON calculations. The velocity distribution at time $=0.01$ second is shown in Figure 5 to illustrate this effect. The COMPARE code assumes no velocities in its calculations, therefore, the calculated pressures are stagnation pressures.

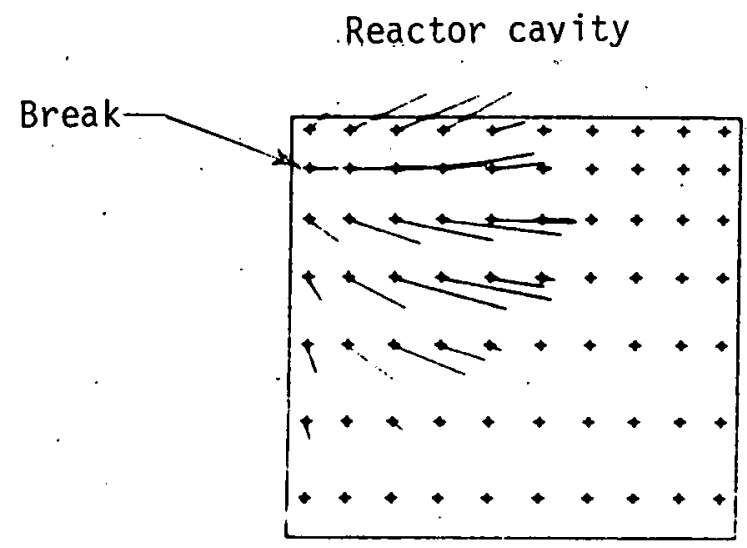

Lengths of the velocity vectors are proportional to the speeds.

Maximum velocity $=132 \mathrm{~m} / \mathrm{s}$

Fig. 5 Pictorial representation of the relative vapor velocity vectors which contribute to the lowered cavity pressures in the BEACON calculations.

(4) Finally, a small part of the pressure differences may possibly be attributed to the inability to model the pipe penetrations very accurately with BEACON. However, since the 
maximum calculated pressure obtained for the containment using COMPARE ( $0.162 \mathrm{MPa})$ and the BEACON constant pressure boundary (0.101 MPa) did not differ significantly, back pressure was not considered to be a large factor. Also, since the direction of flow from both the penetrations and the simulated boundary were at right angles to the general flow within the cavity this method of modeling was probably a good compromise. For these reasons, modeling the penetrations by using the BEACON constant pressure boundary was not believed to introduce significant error.

\section{FORCE AND MOMENT LOADS ON THE REACTOR PRESSURE VESSEL}

Calculated pressures within the Arkansas-1 cavity were used to obtain the force and moment loads on the Arkansas-1 reactor pressure vessel. For these calculations, the positive $Z$-axis was considered to be upward through the pressure vessel centerline, the positive $Y$-axis was outward through the hot leg break, and the positive $X$-axis was outward at $90^{\circ}$ counterclockwise from the $Y$-axis.

Since the Arkansas-1 problem was symmetrical about the hot leg break, the $X$-forces were essentially zero using both codes. The calculated horizontal $Y$-forces on the pressure vessel were significantly. less using BEACON, rather than COMPARE, but the vertical $Z$-forces were slightly higher (Figure 6 ). The horizontal forces were less because the BEACON cavity pressures were smaller as explained in Section IV.1. The vertical forces on the vessel were greater with BEACON because the lower sub-cavity pressurized faster than with COMPARE. For example, at 0.5 second into the LOCA, the pressure in the sub-cavity using BEACON was 30\% higher than the corresponding COMPARE value. This faster pressurization of the sub-cavity is again believed to be 


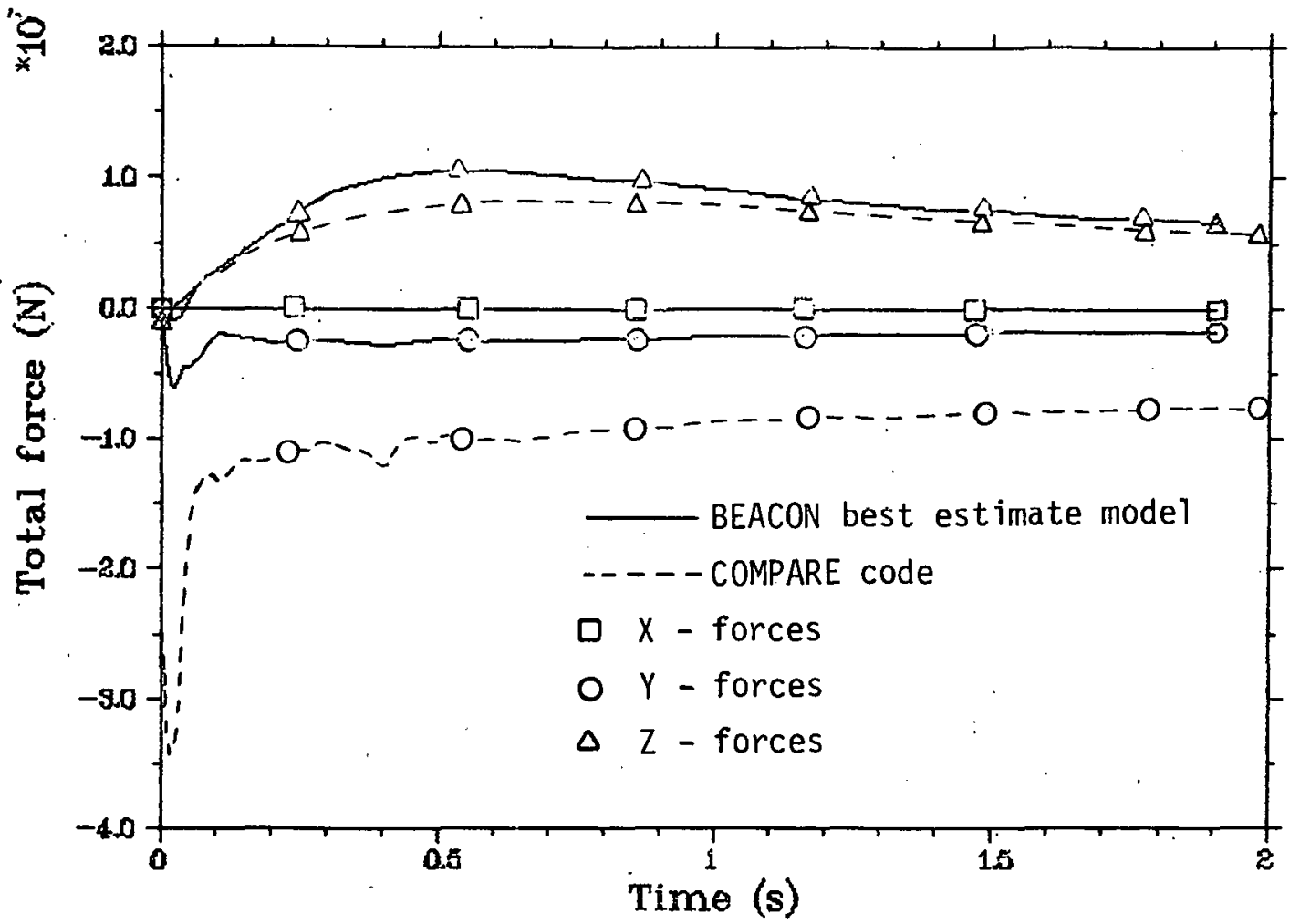

Fig. 6 Comparison of BEACON and COHPARE calculated forces on the reactor pressure vessel during the hypothetical LOCA.

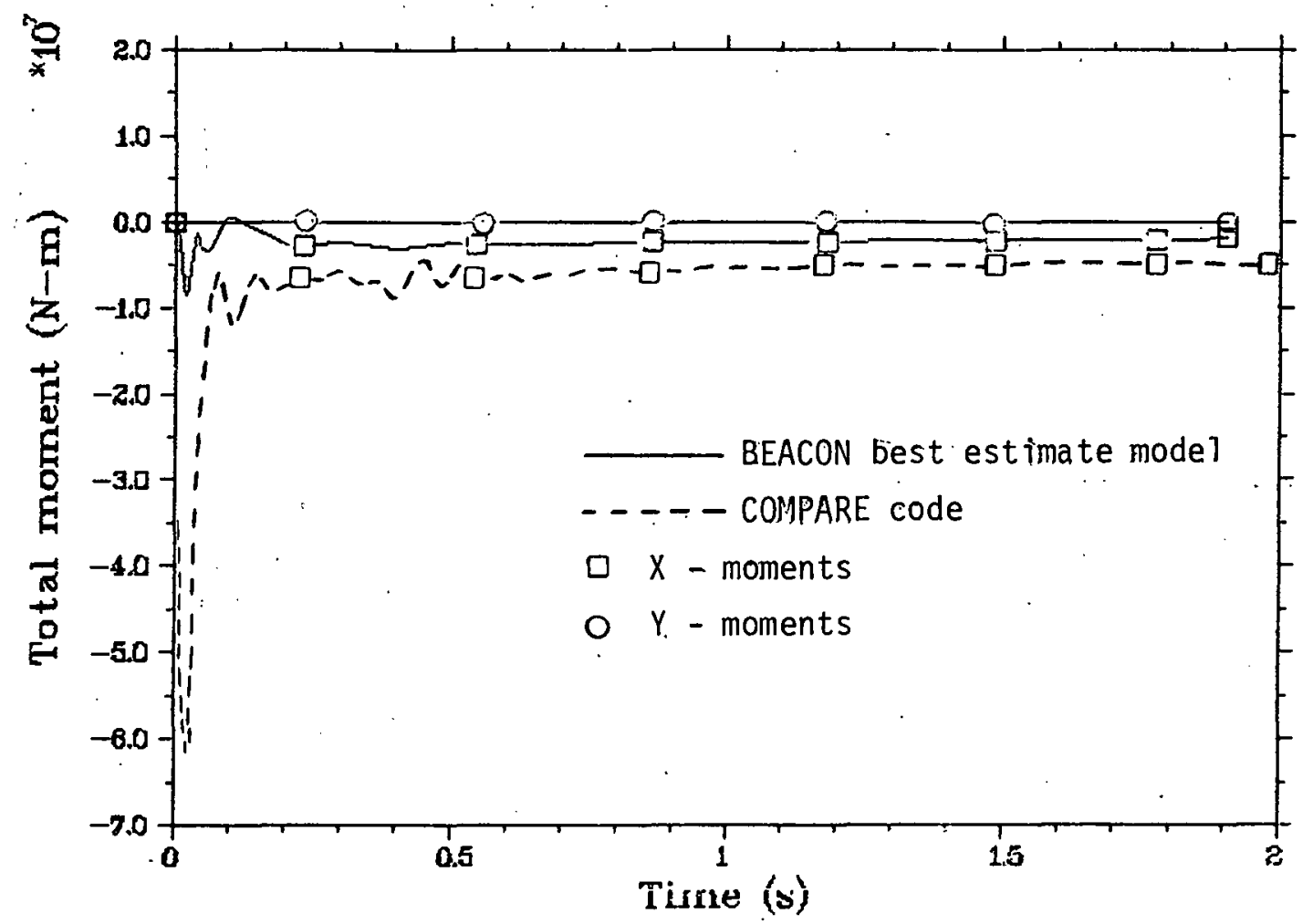

Fig. 7 Comparison of BEACON and COMPARE calculated moment loads on the reactor pressure vessel during the hypthetical LOCA. 
due to the non-homogeneous features in BEACON, allowing a higher mass flow rate of cool air from the cavity into the sub-cavity.

The predicted moment loads on the pressure vessel from both codes are compared in Figure 7. Again, the BEACON values fall well below those from COMPARE because of the lower calculated pressures.

\section{PARAMETRIC STUDIES}

A study was made to investigate the effects of varying the flashing rate, drag, interphasic heat transfer, and timestep control parameters on the calculated pressures during a LOCA. Variations were made to the best estimate model for these parametric studies. The film and heat structure options were also investigated to ensure that the wall heat transfer models were operating properly. Results are discussed below.

Flashing Rate. The BEACON flashing rate correlation determines the evaporation rate as a function of the amount of liquid superheat (difference between the liquid and local saturation temperatures). An investigation of the significance of changes to this correlation was made by varying a multiplier on the flashing rate, LAMBDA. Five computer runs were made (Runs 2 through 6) varying. LAMBDA from 0 to 10 , however, the case with LAMBDA equal to 10 did not run: Changing the flashing rate affected the BEACON results more than changing any of the other parameters which were investigated. The resulting peak cavity pressures varied from 0.3 to $4.2 \mathrm{MPa}$ during the first 0.05 second of the LOCA (Figure 8 ). A value of 0.3 for. LAMBDA gave an initial peak pressure (at 0.01 second) that closely approximated the COMPARE results. However, results calculated with LAMBDA greater than or equal to 0.3 showed some evidence of pressure oscillations early in : 


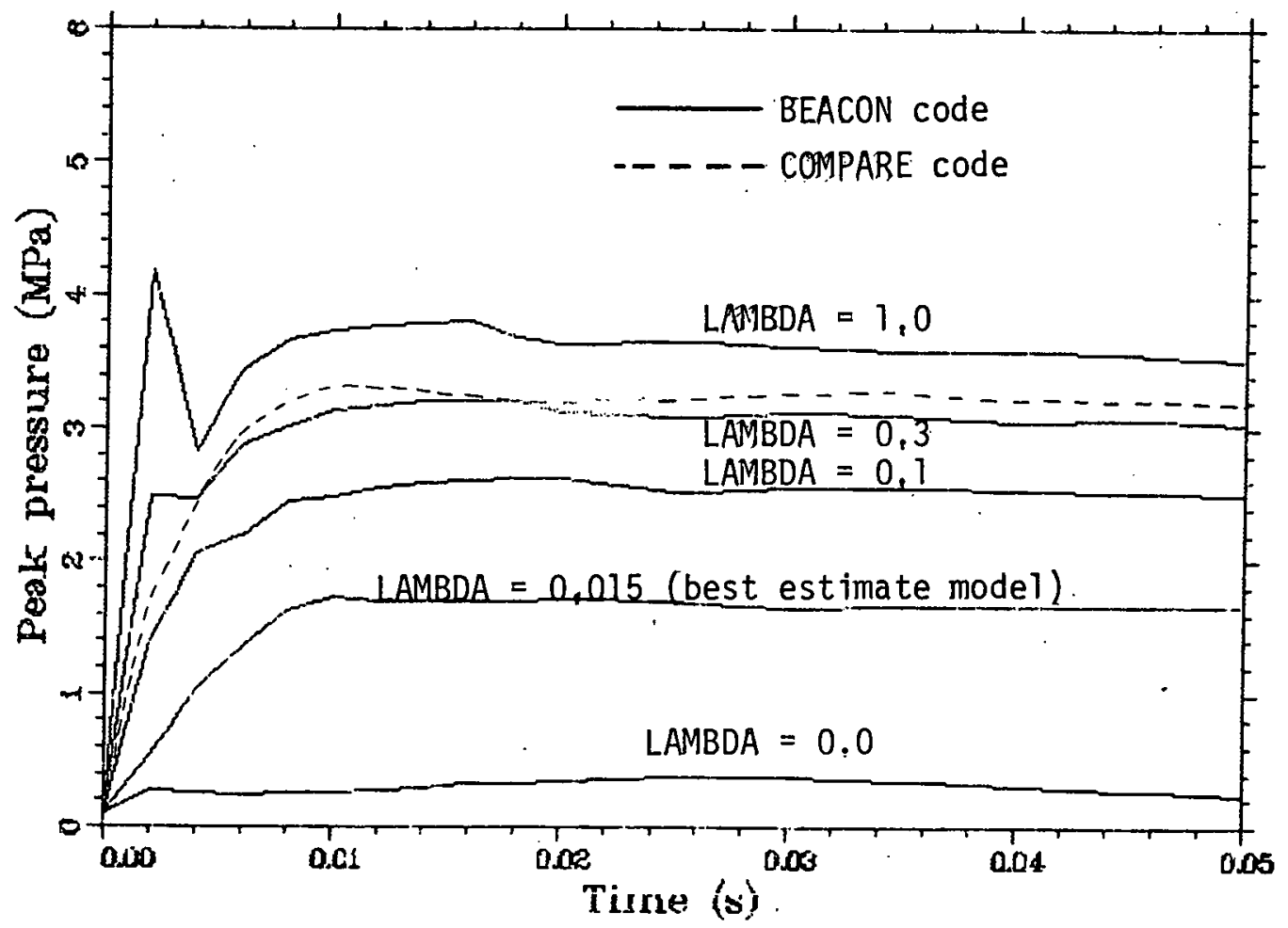

Fig. 8 BEACON peak cavity pressure variations with changes in the flashing rate multiplier (LAMBDA). 
the LOCA. These results do reflect possible physical phenomena. With $\angle A M B D A=10$, the high evaporation rate forced the code to go numerically unstable.

The flashing rate also had an effect on the problem time. As the flashing rate was increased, the computing time also increased (Table I).

Interphasic Drag. The BEACON interphasic drag coefficient (KDRAGI) and velocity vector differences determine the momentum exchange between the liquid and vapor. This correlation determines the amount of coupling between the phases. To investigate what effect this correlation has on the Arkansas-1 results, the BEACON constant drag coefficient (KDRAGI) was varied from 0.0 to $2.2 \mathrm{E} 10$ (Runs 7 through 10). The resulting peak pressures during the first 0.05 second varied from about 0.9 to $1.7 \mathrm{MPa}$ (Figure 9). With values of KDRAGI greater than or equal to 2.2E8 there were no changes in calculated pressures, indicating that the unequal velocity capabilities of the code were essentially nullified. It would appear that a drag parameter above 2.2E8 does not further affect the results in this problem.

Computing time decreased with increasing values of KDRAGI. This occurred because a higher KDRAGI represented tighter coupling between the two phases, nearly equal velocities, and, therefore, fewer iterations.

Interphasic Heat Transfer. The BEACON interphasic heat transfer rate . is the product of an interphasic heat transfer coefficient (RHEATI) and the temperature difference between the two phases. An investigation was made to determine the effects of varying this coefficient on the Arkansas-1 results. In the BEACON best estimate model, the overall interphasic heat transfer coefficient (RHEATI) was set to 1.0E20 which dictated essentially no temperature differences between the 


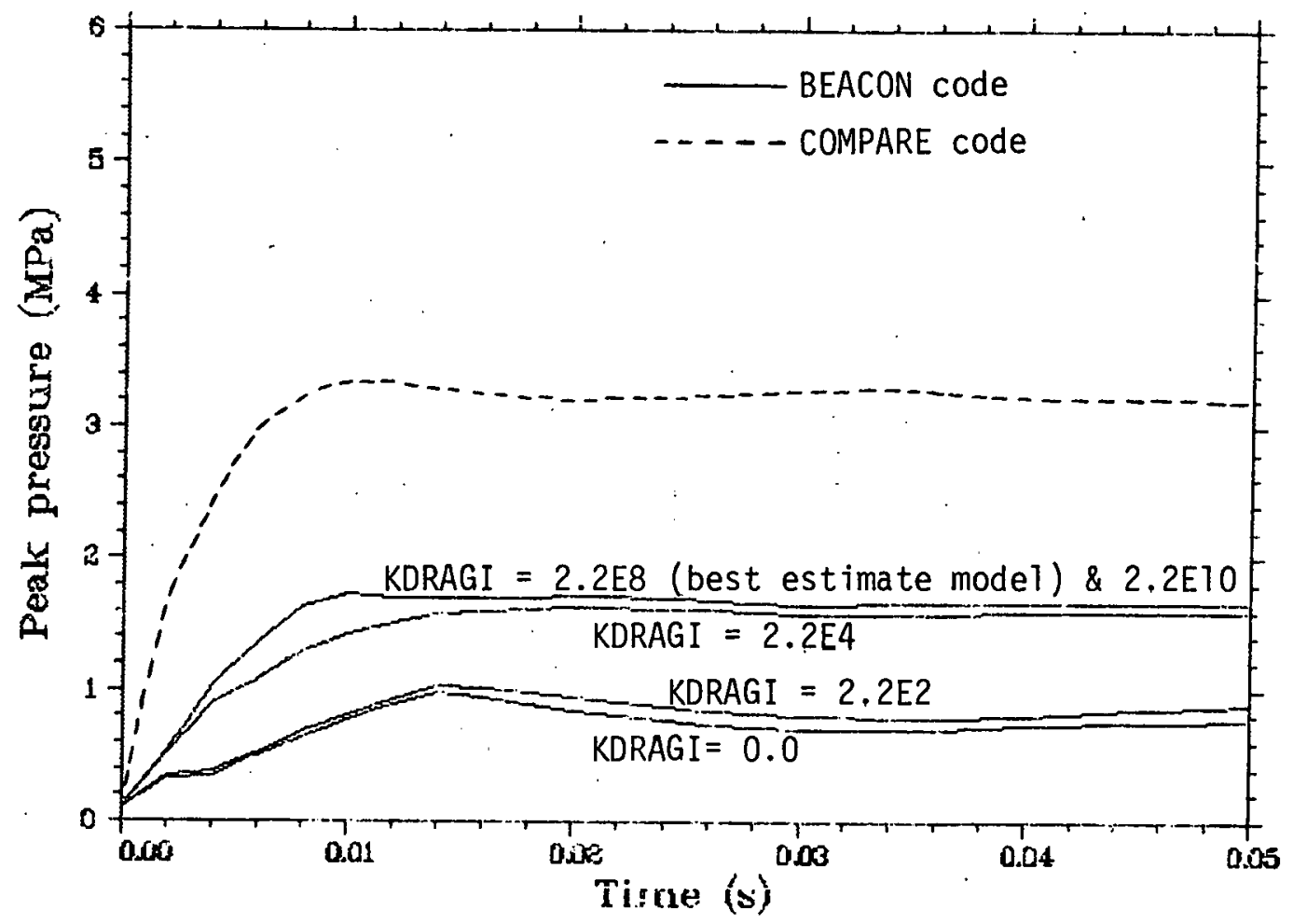

Fig. 9 BEACON peak cavity pressure variations with changes in the interphasic drag parameter (KDRAGI). 
liquid and vapor phases. This nullified the unequal temperature capabilities of the code. RHEATI was changed to 1.0 E10 and $1.0 E 7$ in Runs 11 and 12, respectively, to investigate the effect on the resulting peak cavity pressures. With RHEATI $=1.0 \mathrm{E} 10$, the pressures were the same as with the best estimate model (Run. 1). When RHEATI was set to $1.0 E 7$ the results showed slight pressure oscillations, but pressures remained within $10 \%$ of those from the best estimate model. Results could not be obtained with values of RHEATI less than $1.0 E 7$.

Timestep Control. The Arkansas-1 best estimate model was run with the automatic timestep option, allowing internal calculation of the timestep based on certain restrictions (output frequency, Courant multiplier, lumped parameter region timestep, etc.). An investigation of the effects of varying the timestep control parameters was needed to determine whether significant differensss in results and computing time would occur. For the parametric studies, several of the timestep options were varied (Runs 13 through 20, Table I).

When the problem was run with constant timesteps of 0.0001 and 0.00001 second (Runs 13 and 14) the resulting pressures were not significantly different than with the automatic timestep (Run 1). The initial peak pressures (at 0.01 second) were slightly higher (about $10 \%$ ) than with the best estimate model but converged shortly thereafter (Figure 10). Computing time using a timestep of 0.0001 second was only about $40 \%$ higher than with the best estimate model (autotimestep). This occurred because the average internally calculated timestep from Run 1 was close to 0.0001 second. The problem run with a constant timestep of 0.00001 second (Run 14) took four times as much computer time as the other two cases to run only to 0.025 second. Even though the constant timestep cases are thought to be more accurate, the small differences in results obtained probably do not warrant the extra running expense. 


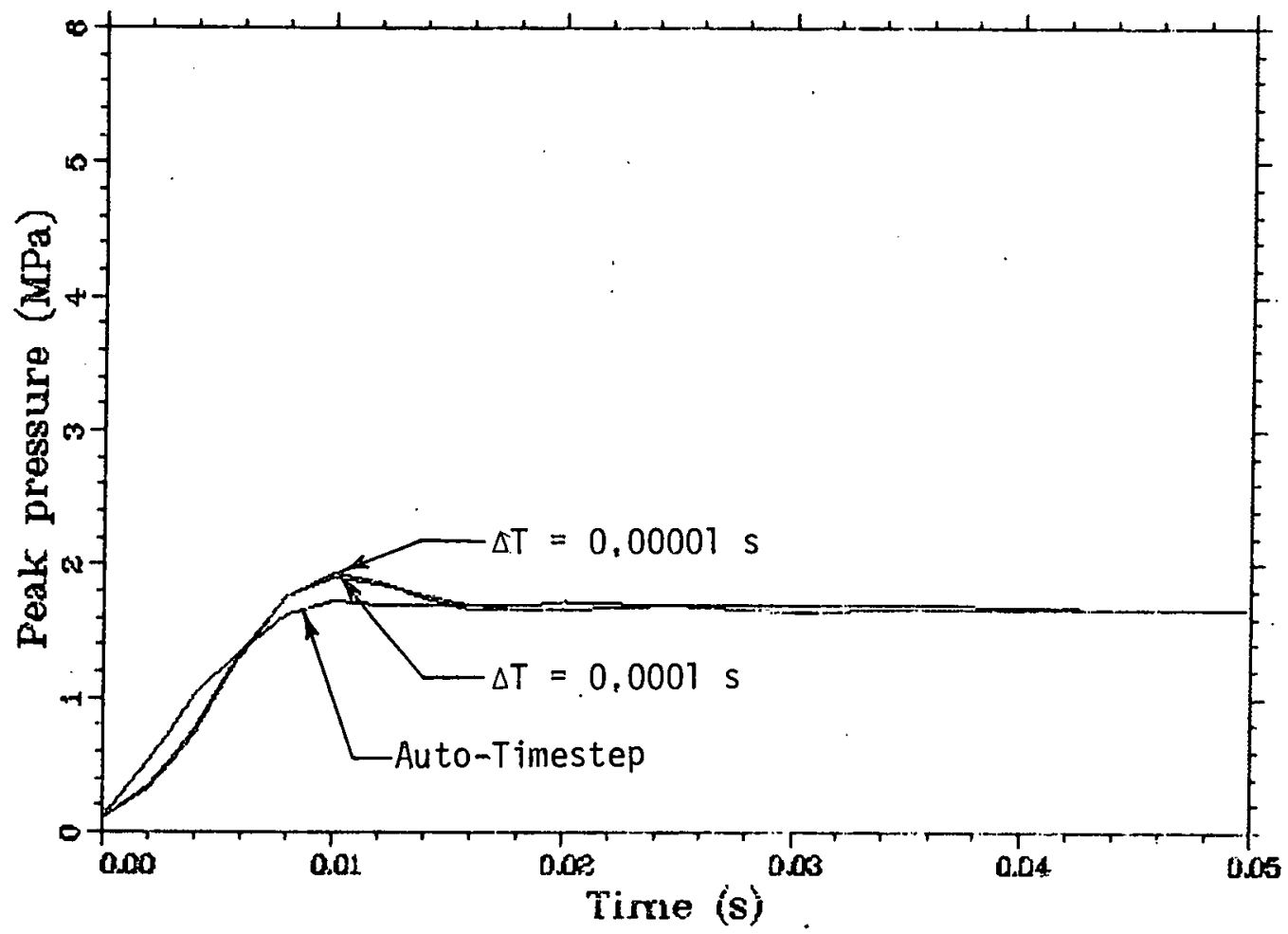

Fig. 10 BEACON results showing the effect that timestep has on calculated peak pressures. 
The effects of varying the Courant restriction multiplier (XDTC) were investigated in Runs 15 and 16. This multiplier limits the calculational timestep to a given fraction of the internally calculated timestep when using the BEACON automatic option. Running the problem out to 2 seconds with XDTC $=0.5$ resulted in a very short CPU time (747 seconds versus 2928 seconds for the best estimate model) and the peak pressures were about 10\% higher than those from Run 1. However, the lumped parameter region timestep restriction set for this case limited the problem timestep to a maximum of 0.001 second. It was interesting to note that results similar to the other runs could be obtained with such a short CPU time. With XDTC $=0.05$ and a problem time of 0.05 second, the results were again less than $10 \%$ higher than those of the best estimate model (XDTC $=0.10$ ) but the CPU time was about $70 \%$ higher. Judicious use of this parameter appears to be a good way to save computer time.

The relaxation parameter (OMEGA) is used by BEACON in iterating on the pressures. Higher values for OMEGA force over-relaxation in the iteration process and may be more efficient than using no relaxation (OMEGA=1.0) under some situations. An investigation was made to determine the effects of increasing the relaxation parameter to 1.5 and 2.0 (Runs 19 and 20). For the value of 1.5, the CPU time doubled but results were the same as with the best estimate model $(O M E G A=1.0)$. Using OMEGA $=1.0$, the average number of iterations per cycle was 2.7. With $O M E G A=1.5$, this value jumped to 47.5 per cycle. Using OMEGA $=1.5$ forced the code to use too high of an over relaxation and the result was many more iterations than were necessary. The code would not run with OMEGA $=2.0$. These results point out the need to choose the relaxation parameter carefully to save execution time. Further study is necessary to bracket the optimum value for OMEGA to a narrower range. 
Wall Heat Transfer. The new MOD2A wall heat transfer options were investigated to ensure that the models were operating correctly and to observe the effects on calculated pressures. The best estimate model was used with the addition of wall film and heat structures and was run to 0.05 second (Run 21, Table I). As expected, negligible changes in peak pressures were observed because of the large mass flow into the cavity and the short problem time. The addition of the film and wall heat transfer calculations to the best estimate model added about $50 \%$ to the CPU time. 


\section{CONCLUSIONS AND RECOMMENDATIONS}

Modeling the Arkansas-1 reactor cavity with BEACON during the postulated LOCA was quite straightforward except for modeling the hot and cold leg pipe penetrations. A constant pressure boundary was used to simulate these penetrations and worked acceptably. However, inclusion of outflow capabilities within the interior of the mesh to more closely approximate the real flow from the cavity would be an asset in the code.

Results from the BEACON analysis of the hypothetical Arkansas-1 LOCA are believed to be more realistic than the COMPARE results. The two-dimensional, non-equilibrium features in BEACON coupled with the flashing rate and drag options are thought to more closely approximate physical phenomena than the COMPARE code. Peak pressures calculated by BEACON remained about 50\% lower than those of COMPARE throughout the LOCA. Pressure distributions around the annulus were similar, except for magnitude, using both codes. The lower pressures calculated by BEACON were thought to be the result of the non-homogeneous features of the code, the time lag introduced by the flashing rate, and velocity effects.

Several conclusions were obtained from the parametric studies where the BEACON flashing rate, drag, interphasic heat transfer, timestep control, wall film, and heat structure parameters were investi-. gated:

(1) The flashing rate parameter seemed to have the most pronounced effect on calculated pressures. However, the value chosen for this parameter can be considered only arbitrary until an accurate way of modeling the particle density has been developed 
(2) Variations in calculated pressures were also seen with increasing values of interphasic drag. Again, this parameter probably should not be a constant value, but should vary with particle density

(3) Variations in calculated pressures with differing values of the interphasic heat transfer rate were generally insignificant (less than 10\%). However, the code exhibited evidence of instability with lower values of this parameter. Further investigation of the causes of this instability needs to be done.

(4) The most accurate pressure predictions during the LOCA were probably obtained with the small constant timestep $(0.00001$ second $)$. However, the automatic timestep was used successfully with only small differences (10\%) in results. For most problems, it is probably sufficient to allow the code to calculate results using this option.

(5) Results from the Arkansas-1 analys is pointed out the value in carefully selecting the timestep control parameters. Large savings in computing time were realized by experimenting with the timestep, Courant multiplier, and relaxation parameters.

(6) By experimenting with the Courant multiplier, it was demonstrated that the Arkansas-1 LOCA could be modeled with BEACON using nearly the same computer time as the COMPARE code. The added accuracy of using a dynamic, twodimensional code such as BEACON was realized with only a $20 \%$ increase in CPU time. In addition, the pressure predictions remained within about $10 \%$ of those using a much smaller timestep. 
(7) As expected, the addition of wall film and heat transfer resulted in negligible effects for this problem.

The predictions of pressures and resulting loads in a PWR cavity during a LOCA using BEACON/MOD2A indicate that all of the models investigated appear to be operating correctly, except possibly the interphasic heat transfer option. The calculations seem to give reasonable answers and there are no deviations from expected physical trends. The initial problem setup and modeling time was small and involved only a few simple calculations. Changes were easily made once the problem was defined. 


\section{REFERENCES}

1. R. G. Gido et al, COMPARE: A Computer Program for the Transient Calculation of a System of Volumes Connected by Flowing Vents) LA-NUREG-6488-MS (September 1976).

2. Letter report: W. J. Mings to B. F. Saffe11, "PWR PRESSURE VESSEL SUPPORTS - WJM-3-78," September 27, 1978.

3. Letter report: R. A. Pate to R. A. Wells, "BEACON SAMPLE PROBLEMS - PAT-2-77," December 6, 1977.

4. J. A. Ramsthaler, BEACON Containment Code Analys is of the Battel le-Frankfurt D-1 Experiment, CDAP-TR-78-021 (September 1.978). 
APPENDIX A

BEACON INPUT

A-1 
100 'ARKANSAS-1 REACTOR CAVITY HOT LEG BREAK'

******8EST-ESTIMATE MODEL

*******VARIABLE MESH WITH PARISAL FLOW 8LOCKAGES FOR PIPES

***** \#UTLETS MODELED AS CONSTANT PRESSURE BOUNDARIES

******* INSTRUMENT TUBES MODELED BY PARTIAL FLOW BLOCKAGE

***** * CUTLETS MODELED THRU SKIRT INTO LOWER SUBCAVITY

******* * LARGE JET FLASHING, DRAG, AND HEAT TRANSFER PARAMETERS

$\star * * * * *$

$* * * * * * *$

$* * * * * *$

LAMBDA $=0.015 \quad$ KDRAGI $=2.2 E 8$

RHEATI $=1.0 E 20$

$1 \frac{1}{20}$

$0.0,2.00, .0001$, SEC, 10., 1, NOXEQ

130

140

150

160

170 .

180

200

210

220

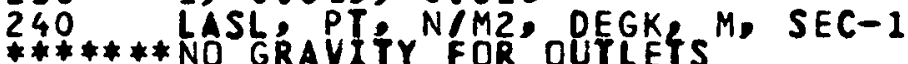

$0.002, .02,0.005, .05,0.010, .10,0.100,2.00$

AUTOOT, 0 , I0, 2.0

PRINT, NOPRINT, NOPRINT, NOPRINT, NOPRINT, 99999

NÓPLOTS, $0.9,1,1,0,0,0,0,0,0,0,1,0.0$

MULTI, VARI, NOOFLCPT

1, $2,001,3,4.4$

$1: 0,0,0001,0.0001,300,5$, , 109

$1: 5 E-4,20.8 E-69$ FT2/SEC, 1.0, 1.0, MM, $100.00, M 3,2.2 \mathrm{E}, 1$

11000 CARTSN, 10, 7, 61 , 61

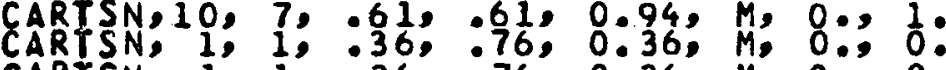

31000

41800

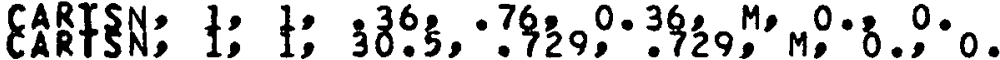

11010 SLIP, SLIP, NOSLIP, NOSLIP

$110200.70,0.92,0.92,0.95,1.03,1.03,0.95,0.92,0.92,0.70$

11030

1101

$1.52,1.52,1.52,1.22,1.10,0.94,0.58$

MIXIURE, 2, 2, 11,8, 0, 1.01353E5, 311., 311., $1.000,0.96$

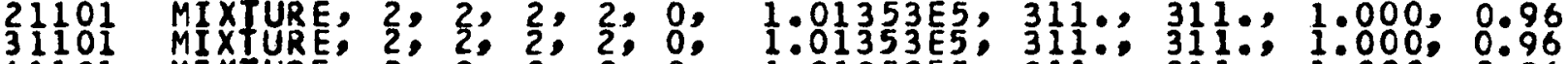

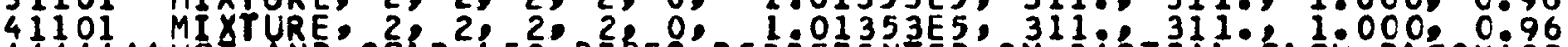
******HOT XND COLD LEG PIPES REPRESENTED BY PARTIAL FLOW BLOCKAGE

$\frac{1}{1} 1301302,8 ; 5 ; 7 ; 0: 10 ;: \frac{1}{1} ;:$ :

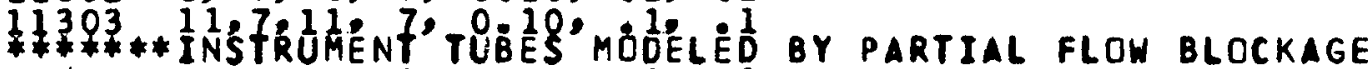

11304 4? $2,4,8,0.69,: 1 ;: 1$

******1UMPED PARAMETER REGION

*******USED FULE VOLUME TO AGREE WITH ICOMPARE RUN

12000 ZEBOP, $23,933,1.0 E 20,0.015,0.015$

12010 MIXPRE, i.01353E5, 311., 311:, i.000, 0.96

******HALF THE FLOWRATES ARE USED SINCE HALF THE CAVITY IS MODELED

*******BREAK CONOITIONS GIVEN IN ENGLISH UNITS

3010 LIOUID, I, $2,7,3011,0 .$, RADIANS, 0.5

3011 SEC, LB/SEC, BTU/LB, FT, SEC-1

$30120.00000,1.14720 E 5,6.16160 \mathrm{E} 2,0$.

$3013 \quad 0.05005,1.0583755,6.16405 E 2: 0:$

3015 . $0.30002,1.00176 \mathrm{E}, 6.18752 \mathrm{E}, 0$.

$3016 \quad 0.40005,1.07820 E 5,6: 19716 E 2,0$ :

$3017 \quad 0.50001,9.78461 E 4,6.17999 E 2,0$.

$3018.0 .60004,9.77577 E 4,6.13860 \mathrm{E}, 0$.

$30190.70000,9.65971 E 4,6.10912 E 2,0$.

$3020 \quad 0.80003,9.20385 E 4,6.10842 E 2,0$ :

$3021 \quad 0.90006,9.03305 E 4,6.10210 E 2,0$ :

3022 1.00002, 8.55507E4, 6.1105IE2; 0 .

$3023 \ldots-1.20001,8.08165 E 4,6.12674 E 2,0$.

, 0.

3025
$3026 \quad 2.00000 \%, 7.30820 E 4,6.18534 E 2: 0$

$* * * * * *$

IIIOI CONSTP; 2, 9, 10,9

11601 MIXTURE, $1.01353 E 5,311 \ldots, 311 \ldots, 1.000,0.96$

41501 CDNSTP, 3, 2,3,32, $311,311,1.000,0.96$

6001 8OffoM: $1 ; 5 ; 2 ; 1 ; 2 ; 2 ; 2 ; 1$

7001 BOIfOM: $\frac{2}{30}, 2 ; 2 ; 1 ; 1: 0$

7003 LEFT, $4,2,2,2,1,1.0^{\circ}$

Fig. A-1 BEACON input card listing for the Arkansas-1 cavity hot leg break best estimate model. 